\title{
ORIGINAL ARTICLE \\ Development of the International Spinal Cord Injury Activities and Participation Basic Data Set
}

\author{
MW Post ${ }^{1,2}$, S Charlifue ${ }^{3}$, F Biering-Sørensen ${ }^{4}$, A Catz $^{5}$, MP Dijkers ${ }^{6}$, J Horsewell ${ }^{7}$, VK Noonan ${ }^{8}$, L Noreau ${ }^{9}$, \\ DG Tate ${ }^{10}$ and KA Sinnott ${ }^{11}$
}

\begin{abstract}
Study design: Consensus decision-making process.
Objectives: The objective of this study was to develop an International Spinal Cord Injury (SCI) Activities and Participation (A\&P) Basic Data Set.

Setting: International working group.

Methods: A committee of experts was established to select and define A\&P data elements to be included in this data set. A draft data set was developed and posted on the International Spinal Cord Society (ISCoS) and American Spinal Injury Association websites and was also disseminated among appropriate organizations for review. Suggested revisions were considered, and a final version of the A\&P Data Set was completed.

Results: Consensus was reached to define A\&P and to incorporate both performance and satisfaction ratings. Items that were considered core to each A\&P domain were selected from two existing questionnaires. Four items measuring activities were selected from the Spinal Cord Independence Measure III to provide basic data on task execution in activities of daily living. Eight items were selected from the Craig Handicap Assessment and Reporting Technique to provide basic data on the frequency of participation. An additional rating of satisfaction on a three-point scale for each item completes the total of 24 A\&P variables.

Conclusion: Collection of the International SCl A\&P Basic Data Set variables in all future research on SCl outcomes is advised to facilitate comparison of results across published studies from around the world. Additional standardised instruments to assess activities of daily living or participation can be administered, depending on the purpose of a particular study.
\end{abstract}

Spinal Cord (2016) 54, 530-534; doi:10.1038/sc.2015.188; published online 20 October 2015

\section{INTRODUCTION}

Spinal cord injury (SCI) affects all body functions below the level of the neurological lesion, and people with SCI may therefore experience a wide range of impairments in body functions, activities and participation and quality of life. ${ }^{1,2}$ The typical spectrum of activity limitations and participation restrictions relates to mobility such as transfers and locomotion, self-care activities such as bathing, dressing and toileting, difficulties in regaining employment, maintaining social relationships, participating in leisure activities and being active members of the community. ${ }^{3,4}$ The social, economical and psychological consequences for an individual with SCI are significant and usually lifelong and are the result of a complex interaction of factors, including, but not limited to, acute neurological recovery, medical intervention and support from rehabilitation and social reintegration services. ${ }^{3}$

To facilitate comparisons regarding injuries, treatments and outcomes between individuals with SCI, treatment centers and countries, data collection on living with SCI should be in the form of a common international data set. The International SCI Data Set project was started in Vancouver in 2002 to select elements to be included in International SCI Data Sets. ${ }^{5}$ Basic data sets consist of a minimum amount of data that clinicians might want to collect on most or all individuals with SCI who they serve. Extended data sets are primarily designed for research purposes and are more comprehensive than basic data sets. The International Classification of Functioning, Disability and Health (ICF) ${ }^{6}$ was chosen as the underlying conceptual framework. Accordingly, data sets were to be developed at the levels of body functions and structures, activities and participation, in addition to a core data set of personal and injury characteristics and a data set for quality of life. $5,7,8$

Minimizing activity limitations and participation restrictions are major goals of the comprehensive management of individuals with SCI; thus, there is a need for a common international data set to provide standardised information on activities and participation

${ }^{1}$ Brain Center Rudolf Magnus and Center of Excellence in Rehabilitation Medicine, University Medical Center Utrecht and De Hoogstraat Rehabilitation Centre, Utrecht, The Netherlands; ${ }^{2}$ Department of Rehabilitation Medicine, Center for Rehabilitation, University of Groningen, University Medical Center Groningen, Groningen, The Netherlands; ${ }^{3} \mathrm{Craig}$ Hospital, Englewood, CO, USA; ${ }^{4}$ Department for Spinal Cord Injuries, Rigshospitalet and Glostrup Hospital, University of Copenhagen, Copenhagen, Denmark; ${ }^{5}$ Loewenstein Rehabilitation Hospital, Raanana, and Tel-Aviv University, Tel-Aviv, Israel; ${ }^{6}$ Icahn School of Medicine at Mount Sinai, New York, NY, USA; ${ }^{7}$ The European Spinal Cord Injury Federation, Copenhagen, Denmark; ${ }^{8}$ The Rick Hansen Institute, Vancouver, BC, Canada; ${ }^{9}$ Université Laval and Center for Interdisciplinary Research in Rehabilitation and Social Integration (CIRRIS), Quebec City, QC, Canada; ${ }^{10}$ University of Michigan, Department of Physical Medicine and Rehabilitation, Ann Arbor, MI, USA and ${ }^{11}$ Burwood Academy of Independent Living, Christchurch, New Zealand

Correspondence: Professor MW Post, Brain Center Rudolf Magnus and Center of Excellence in Rehabilitation Medicine, University Medical Center Utrecht and De Hoogstraat Rehabilitation Centre, Rembrandtkade 10, Utrecht 3583TM, The Netherlands.

E-mail: m.post@dehoogstraat.nl

Received 14 February 2015; revised 23 May 2015; accepted 27 May 2015; published online 20 October 2015 
outcomes. The aim of the current work is to describe the development, scope and content of the International SCI Activities and Participation (A\&P) Basic Data Set.

\section{MATERIALS AND METHODS}

The International SCI A\&P Basic Data Set was created by a working group of experts in SCI participation and quality of life research, together with representatives of the Executive Committee of the International SCI Standards and Data Sets. This group has also been responsible for the development of the International SCI Quality of Life Basic Data Set. ${ }^{8}$ The development process for the International SCI A\&P Basic Data Set involved the following steps:

(1) The working group developed a first draft data set. Main decisions, described in the Results section of this paper, were made during a 3-day meeting in Copenhagen in October 2008, and the results further refined through frequent e-mail communication among the group members over the next 2 years.

(2) The draft data set was reviewed by members of the Executive Committee of the International SCI Standards and Data Set project.

(3) Comments from the Committee members were discussed among the working group via e-mail, and appropriate changes were made.

(4) Members of the International Spinal Cord Society (ISCoS) Scientific Committee and the American Spinal Injury Association Board of Directors were asked to review the refined data set.

(5) Comments from the Committee/Board members were discussed by the working group via e-mail, and further adjustments were made.

(6) Relevant and interested national and international scientific professional organizations and societies, as well as interested individuals, were invited to review the data set. In addition, it was posted on both the ISCoS and American Spinal Injury Association websites for 3 months with a request for comments and suggestions. Comments were reviewed by the working group, and, based on this feedback, some further minor changes were made.

(7) The data set was finalized by August 2012, having undergone only minor revisions after the development of the first draft, and was published on the ISCoS website later that year.

(8) Standard naming of the variables of the data set was completed in collaboration with the National Institutes of Health, National Institute of Neurological Disorders and Stroke Common Data Element project. ${ }^{9}$

(9) Endorsement of the final data set was sought from relevant international organizations and societies. The names of the organizations and societies that endorse this Basic Data Set will be posted on the ISCoS website (www.iscos.org.uk).

\section{RESULTS}

Conceptualization of activities and participation

Activity limitations are defined in the ICF as difficulties an individual may have in the execution of a task or an action and participation restrictions as problems an individual may experience in involvement in life situations. ${ }^{6}$ Activities and participation are distinct conceptual entities in the well-known ICF model, but the ICF A\&P classification contains a single list of entries with four different options to distinguish between activities and participation (World Health Organization $^{6}$, 234ff). This apparent inconsistency in the model has prompted many empirical and opinion papers on this issue, ${ }^{10-13}$ and it was clear that consensus was not to be expected. Therefore, in the development of the A\&P Basic Data Set, a pragmatic approach was chosen, meaning that it would not be necessary to make a choice at all - as long as it was possible to reach consensus on the selection of the most important domains from the list of activity and participation chapters.

\section{Coverage of the data set}

The A\&P Basic Data Set should be very brief so that it could be used in clinical practice. It should not aim to cover all domains listed in the ICF A\&P classification but contain only the minimum number of items that all clinicians should record on individuals with SCI seen in their clinical practice. The working group selected items for the A\&P data set that cover categories in the ICF chapters 4 (Mobility), 5 (Selfcare), 6 (Domestic life), 7 (Interpersonal interactions and relationships), 8 (Major life areas) and 9 (Community, social and civic life).

It was decided to focus within the mobility domain on walking or using a wheelchair and to leave out items on bed mobility, sitting, standing, transfers and using public or private means of transportation. Also, items on carrying, moving and handling objects were left out, as it was assumed that problems in the use of arms and hands would be captured in the self-care domain. Within this self-care domain, feeding, dressing and toileting were considered core activities to be included as separate items. Other items were assumed to reflect similar levels of activity, for example, washing and dressing or eating and drinking.

One item on household work, including raising children (parenting), housekeeping and food preparation, was selected to cover Domestic life. Concerning Major life areas, it was decided to include items on paid work, unpaid work (volunteering) and pursuit of an education. Economic life, for example, the ability to engage in financial transactions and having economic resources, was discarded as being less of an issue in individuals with SCI and constituting an indicator of socioeconomic status and therefore being a candidate item for another data set, respectively. The domain of Interpersonal interactions and relationships was split up into relationships with a spouse, with family members and with friends. Finally, one item on leisure (spare time activities) was selected to represent the chapter on community, social and civic life.

\section{Timing of collecting data on activity and participation}

Data on self-care and mobility can be collected at any time from the start of initial rehabilitation to long-term follow-up. It is, however, advised to also use this data set to record the preinjury situation to provide a 'baseline' against which the status post-SCI onset can be compared. Data on occupation and relationships are most relevant in the chronic phase. Community integration might take months or even years to reach a relatively stable level. ${ }^{14}$ Repeated collection of data is therefore recommended.

\section{Rating of activity and participation}

A\&P can be described as task execution or behaviors (outsider perspective) and from the point of view of perceived difficulty or satisfaction with task execution or behaviors (insider perspective). ${ }^{13}$ Performance ratings provide insight in the actual functioning of individuals with SCI in the rehabilitation setting or in the community. The recording of the difficulty ratings or satisfaction experiences of the person with SCI as part of a basic data set is necessary, as functioning, especially social functioning, may be judged differentially depending on personal preferences and cultural norms. Correlations between objective and subjective participation are often $\operatorname{seen}^{15}$ but are not a given. Opinions on which perspective is most important diverged in the working group, and as the two perspectives are equally needed to provide complete information, both have been included in the A\&P Basic Data Set.

\section{Use of existing measures for activity and participation}

Numerous measures for A\&P are available, ${ }^{16}$ but, unfortunately, none could be found that covered all six ICF chapters and included performance and satisfaction ratings. Items on mobility and self-care are common in many functional status measures. Items on occupation and social relationships could be taken from participation measures. 
Table 1 Items of the International Spinal Cord Injury Activities and Participation Basic Data Set

\begin{tabular}{lll}
\hline Item & Performance metric & Experience metric \\
\hline Mobility & Task execution & Satisfaction \\
Dressing & Task execution & Satisfaction \\
Feeding & Task execution & Satisfaction \\
Toileting & Task execution & Satisfaction \\
Paid work & Hours a week & Satisfaction \\
Volunteer work & Hours a week & Satisfaction \\
Education & Hours a week & Satisfaction \\
Household work & Hours a week & Satisfaction \\
Spare time activities & Hours a week & Satisfaction \\
Spouse relationships & Presence and type of relationship & Satisfaction \\
Family relationships & Number of contacts & Satisfaction \\
Friends relationships & Number of contacts & Satisfaction \\
\hline
\end{tabular}

A review of functional measures found both the Functional Independence Measure and the Spinal Cord Independence Measure III (SCIM III $)^{17}$ as valid and reliable instruments, with most support for the use of the SCIM to assess global activity limitation in individuals with SCI. ${ }^{18}$ Items on mobility and self-care were therefore taken from the SCIM. The SCIM rates the level of independence and the use of aids in a particular domain. One of the three mobility items (moderate distances), an item on feeding, one on toileting and one of the two dressing items (lower body) were selected.

Two existing reviews of participation measures showed the Craig Handicap Assessment and Reporting Technique $(\mathrm{CHART})^{19}$ to be the most widely used and best researched instrument. ${ }^{20,21}$ Items on participation were therefore taken from the CHART. The selected items in the occupation domain (work, unpaid work, homemaking and education) rate the number of hours spent on each activity per week. The items in the social relations domain rate the size of one's social network (having a spouse, number of family members and friends). The CHART items were slightly adapted by specifying a time frame of 4 weeks.

As both the SCIM and the CHART are performance measures, the working group added a rating of satisfaction with functioning in each domain that uses a three-point verbal rating scale of $0=$ not satisfied, $1=$ somewhat satisfied and $2=$ very satisfied.

\section{Activity and participation basic data set}

The A\&P Basic Data Set thus consists of 8 items relating to chapters 4 and 5 of the ICF and 16 items relating to chapters 6-9. The structure of the A\&P Basic Data Set is displayed in Table 1. To ensure that data are collected in a uniform and in a consistent manner, each variable has been explicitly defined. The complete data set form is included as Appendix 1. The data syllabus and data sheet are available on the ISCoS website (www.iscos.org.uk).

\section{DISCUSSION}

The International SCI A\&P Basic Data Set was developed to collect standardised basic information on activity limitations and participation restrictions in people with SCI. It is applicable to adult individuals with traumatic or non-traumatic spinal cord lesions. Use of a standard format is essential for combining and comparing data from multiple investigators and locations. ${ }^{5}$ The A\&P component of the ICF covers all areas of daily life and has a hierarchical structure of 9 chapters, 118 2-digit categories and 4003 - and 4-digit categories. ${ }^{6}$ This A\&P Basic
Data Set with $12^{\star} 2$ items and, including one variable for data of assessment, a total of 25 variables seems therefore an efficient way to collect data on these important areas in the lives of individuals with SCI.

The A\&P Basic Data Set has not yet undergone psychometric testing, but some confidence in its use might be justified as its items were taken from established measures. Although the A\&P Basic Data Set, like all International SCI Data Sets, has not been designed as a measurement instrument for clinical assessment, psychometric criteria such as test-retest reliability apply and should be examined in future research. Presentation of this data set in languages other than (US) English will require translation of the various components. The working group recommends that a careful translation process be used that follows the published guidelines for translating the International SCI Data Sets. ${ }^{22}$ Although linguistic equivalence may be attained, further research has to indicate to what degree there is functional equivalence in various languages.

It is recommended that, pending validation, this A\&P Basic Data Set be used in all appropriate SCI studies and be used in clinical practice to record data on living with SCI. This does not preclude the use of additional standardised instruments assessing A\&P or other instruments to assess other constructs. It is recommended that the International SCI Core Data $\mathrm{Set}^{7}$ be completed and used in conjunction with the International SCI A\&P Basic Data Set. The Core Data Set includes information regarding date of birth, date of injury/onset, gender, etiology of lesion and neurologic status. ${ }^{7}$ An Extended SCI A\&P Data Set may be warranted for specific research projects and questions involving activities and participation following SCI. The group that developed the Basic A\&P Data Set is awaiting results of the use of this data set before venturing into creation of an advanced data set.

Although not intended as such, with items on mobility and self-care from a functional status measure and items on occupation and social relations from a participation measure, this A\&P Basic Data Set fits a growing consensus on how to specify Activities and Participation, respectively. Most authors are in favor of limiting participation to categories related to involvement in social roles or at least interaction with others. ${ }^{13,23-26}$ On an operational level, a consensus seems to be emerging to consider the ICF chapters $1-5$ to address activities and 7-9 to involve participation. ${ }^{11,13,21,26}$ On the assignment of chapter 6 (domestic life) authors diverge, probably because this chapter covers a mixture of activity-type categories, for example, washing the dishes, and role-type categories, for example, parenting. ${ }^{11,13,26}$

By including both performance and satisfaction items, the A\&P Basic Data Set also fits a trend to include ratings of both performance and satisfaction in participation measures. ${ }^{15,27-29}$ These two perspectives provide complementary information that is useful in research and clinical practice. For example, dissatisfaction with functioning in dressing might indicate a need for additional help, assistive devices or specific environments. ${ }^{30}$ However, practical application and validation will suggest whether it is worthwhile to include both perspectives.

\section{CONCLUSION}

The International SCI A\&P Basic Data Set represents a significant step toward recording and reporting this important information in a standardised way. Although the International SCI A\&P Basic Data Set has been reviewed by the international community of SCI experts, it is anticipated that the data set will require periodic revisions based on findings from studies using it. Ideas for improvement of the A\&P Basic Data Set are welcome and should be forwarded to the corresponding author. 


\section{DATA ARCHIVING}

There were no data to deposit.

\section{CONFLICT OF INTEREST}

The authors declare no conflict of interest.

\section{ACKNOWLEDGEMENTS}

Coloplast A/S Denmark supported this project with an unconditional grant. Dr Gale Whiteneck kindly granted permission to use items from the CHART. We are grateful for comments and suggestions received from Annelie Leiulfsrud, Apichana Kovindha and Eric Weerts.

1 Noreau L, Noonan VK, Cobb J, Leblond J, Dumont FS. Spinal Cord Injury Community Survey: understanding the needs of Canadians with SCI. Top Spinal Cord Inj Rehabil 2014; 20: 265-276.

2 Post MW, van Leeuwen CM. Psychosocial issues in spinal cord injury: a review. Spinal Cord 2012; 50: 382-389.

3 Biering-Sørensen F, Scheuringer M, Baumberger M, Charlifue SW, Post MWM, Montero $\mathrm{F}$ et al. Developing core sets for persons with spinal cord injury based on the international classification of functioning, disability and health as a way to specify functioning. Spinal Cord 2006; 44: 541-546.

4 Cieza A, Kirchberger I, Biering-Sørensen F, Baumberger M, Charlifue S, Post MW et al. ICF core sets for individuals with spinal cord injury in the long-term context. Spinal Cord 2010; 48: 305-312.

5 Biering-Sørensen F, Charlifue S, DeVivo M, Noonan V, Post M, Stripling T et al. International Spinal Cord Injury Data Sets. Spinal Cord 2006; 44: 530-534.

6 World Health Organization. International Classification of Functioning, Disability and Health: ICF. World Health Organization: Geneva, Switzerland, 2001.

7 DeVivo M, Biering-Sörensen F, Charlifue S, Noonan V, Post M, Stripling T et al. International Spinal Cord Core Data Set. Spinal Cord 2006; 44: 535-540.

8 Charlifue S, Post MW, Biering-Sørensen F, Catz A, Dijkers M, Geyh S et al. International Spinal Cord Injury Quality of Life Basic Data Set. Spinal Cord 2012; 50: 672-675.

9 Biering-Sorensen F, Charlifue S, Devivo MJ, Grinnon ST, Kleitman N, Lu Y et al. Incorporation of the international spinal cord injury data set elements into the National Institute of Neurological Disorders and Stroke Common Data Elements. Spinal Cord 2011; 49: 60-64.

10 Jette AM, Haley SM, Kooyoomjian JT. Are the ICF activity and participation dimensions distinct? J Rehabil Med 2003; 35: 145-149.

11 Post MW, Witte LP, de, Reighrath E, Verdonschot MM, Wijlhuizen GJ, Peerenboom RJM. Development and validation of IMPACT: an ICF based questionnaire to measure activities and participation. J Rehab Med 2008; 40: 620-627.

12 Dijkers MPJM. Issues in the conceptualization and measurement of participation: an overview. Arch Phys Med Rehabil 2010; 91: S5-S16.

13 Whiteneck G, Dijkers MP. Difficult to measure constructs: conceptual and methodological issues concerning participation and environmental factors. Arch Phys Med Rehabil 2009; 90: S22-S35.
14 Noreau L, Fougeyrollas P, Post M, Asano M. Participation after spinal cord injury: the evolution of conceptualization and measurement. J Neurol Phys Ther 2005; 29 $147-156$.

15 Brown M, Dijkers MP, Gordon WA, Ashman T, Charatz H, Cheng Z. Participation Objective, Participation Subjective: A measure of participation combining outsider and insider perspectives. J Head Trauma Rehabil 2004; 19 . 459-481.

16 Alexander MS, Anderson KD, Biering-Sorensen F, Blight AR, Brannon R, Bryce TN et al. Outcome measures in spinal cord injury: recent assessments and recommendations for future directions. Spinal Cord 2009; 47: 582-591.

17 Catz A, Itzkovich M, Tesio L, Biering-Sorensen F, Weeks C, Laramee MT et al. A multicenter international study on the Spinal Cord Independence Measure, version III: Rasch psychometric validation. Spinal Cord 2007; 45: 275-291.

18 Anderson K, Aito S, Atkins M, Charlifue S, Curt A, Ditunno J et al. Functional recovery measures for spinal cord injury: an evidence-based review for clinical practice and research. J Spinal Cord Med 2008; 31: 133-144.

19 Whiteneck GG, Charlifue SW, Gerhart KA, Overholser JD, Richardson GN. Quantifying handicap: a new measure of long-term rehabilitation outcomes. Arch Phys Med Rehabil 1992; 73: 519-526.

20 Magasi SR, Heinemann AW, Whiteneck GG. Quality of Life/Participation Committee. Participation following traumatic spinal cord injury: an evidence-based review for research. J Spinal Cord Med 2008; 31: 145-156.

21 Noonan VK, Miller WC, Noreau L, SCIRE Research Team. A review of instruments assessing participation in persons with spinal cord injury. Spinal Cord 2009; 47. 435-446.

22 Biering-Sorensen F, Alexander MS, Burns S, Charlifue S, DeVivo M, Dietz V et al. Recommendations for translation and reliability testing of international spinal cord injury data sets. Spinal Cord 2011; 49: 357-360.

23 Mars GM, Kempen GI, Mesters I, Proot IM, van Eijk JT. Characteristics of social participation as perceived by older adults with a chronic physical illness. Disabil Rehabil 2008; 30: 1298-1308.

24 Magasi SR, Post MWM. A comparative review of contemporary participation measures: Psychometric properties and content coverage. Arch Phys Med Rehabil 2010; 91: S17-S28.

25 Eyssen IC, Steultjens MP, Dekker J, Terwee CB. A systematic review of instruments assessing participation: challenges in defining participation. Arch Phys Med Rehabil 2011; 92: 983-997.

26 Chang FH, Coster WJ. Conceptualizing the construct of participation in adults with disabilities. Arch Phys Med Rehabil 2014; 95: 1791-1798.

27 Dijkers M, Cicerone K, Heinemann A, Brown M, Whiteneck G. PART-S: A new measure of satisfaction with participation. Poster presented at the Annual Meeting of the American Congress of Rehabilitation Medicine, Denver, CO, USA, 7-11 October 2009.

28 Gandek B, Sinclair SJ, Jette AM, Ware JE Jr. Development and initial psychometric evaluation of the Participation Measure for Post-Acute Care (PM-PAC). Am J Phys Med Rehabil 2007; 86: 57-71.

29 Post MWM, van der Zee CH, Hennink J, Schafrat CGWM, Visser-Meily JMA, Berdenis van Berlekom S. Validity of the Utrecht Scale for Evaluation of Rehabilitation-Participation (USER-P). Disabil Rehabil 2012; 34: 478-485; post USE-P.

30 Sweet SN, Noreau L, Leblond J, Dumont FS. Understanding quality of life in adults with spinal cord injury via SCl-related needs and secondary complications. Top Spinal Cord Inj Rehabil 2014; 20: 321-328.

\section{APPENDIX 1}

\section{INTERNATIONAL SPINAL CORD INJURY}

\section{ACTIVITIES AND PARTICIPATION BASIC DATA SET (Version 1.0) FORM}

Please take note of the scoring instructions and time frames in Appendix 2 of the INTERNATIONAL SPINAL CORD INJURY DATA SETS ACTIVITIES AND PARTICIPATION BASIC DATA SET Version 1.0; August 2012 (http://www.iscos.org.uk/international-sci-activity-andparticipation-data-sets)

Date of data collection _ - - I $_{-}$/ $_{-}($YYYY/MM/DD $)$

Performance rating

Mobility moderate distances (10-100 meters) during the last 4 weeks

0 Requires total assistance

1 Needs electric wheelchair or partial assistance to operate manual wheelchair

2 Moves independently in manual wheelchair

3 Requires supervision while walking (with or without devices)
Satisfaction rating

0 Not satisfied

1 Somewhat satisfied

2 Very satisfied

8 Not applicable

99 Unknown 
4 Walks with a walking frame or crutches (swing)

5 Walks with crutches or two canes (reciprocal walking)

6 Walks with one cane

7 Needs leg orthosis only

8 Walks without walking aids

99 Unknown

Dressing lower body during the last 4 weeks

0 Requires total assistance

1 Requires partial assistance with clothes without buttons, zippers or laces (cwobzl)

2 Independent with cwobzl; requires adaptive devices and/or specific settings (adss)

3 Independent with cwobzl; does not require adss; needs assistance or adss only for bzl

4 Dresses (any clothes) independently; does not require adss.

99 Unknown

Feeding during the last 4 weeks

0 Needs parenteral, gastrostomy or fully assisted oral feeding

1 Needs partial assistance with eating and/or drinking or for putting on/taking off adaptive device(s) needed for eating and/or drinking

2 Eats independently; needs adaptive devices or assistance only for cutting food and/or pouring and/or opening containers

3 Eats and drinks independently; does not require assistance or adaptive devices.

99 Unknown

Toileting during the last 4 weeks

0 Requires total assistance

1 Requires partial assistance, does not clean self

2 Requires partial assistance, cleans self independently

3 Independent in all tasks, but needs adaptive equipment or special setting (eg bars)

4 Independent, does not need adaptive equipment or special setting

99 Unknown

Paid work during the last 4 weeks hours a week

99 unknown

Volunteer work during the last 4 weeks hours a week

99 unknown

Education during the last 4 weeks hours a week

99 unknown

Household during the last 4 weeks hours a week

99 unknown

Spare time activities during the last 4 weeks hours a week

99 unknown

Spousal relationship during the last 4 weeks

0 No relationship

1 Married/living together

2 Romantic relationship, not living together

99 unknown

Family relationships (contacts) during the last 4 weeks different family members

99 unknown

Friends relationships (contacts) during the last 4 weeks different friends

99 unknown 